\title{
Diarrhea Disease among Children under 5 Years of Age: A Global Systematic Review
}

\author{
Winfred Mbinya Manetu* ${ }^{\circ}$, Stephen M’masi, Charles W. Recha \\ Department of Geography, Egerton University, Nakuru, Kenya \\ Email: `bnyaw2015@gmail.com, mmasistephen75@gmail.com, charles.recha@egerton.ac.ke
}

How to cite this paper: Manetu, W.M., M'masi, S. and Recha, C.W. (2021) Diarrhea Disease among Children under 5 Years of Age: A Global Systematic Review. Open Journal of Epidemiology, 11, 207-221. https://doi.org/10.4236/ojepi.2021.113018

Received: May 21, 2021

Accepted: June 25, 2021

Published: June 28, 2021

Copyright $\odot 2021$ by author(s) and Scientific Research Publishing Inc. This work is licensed under the Creative Commons Attribution International License (CC BY 4.0).

http://creativecommons.org/licenses/by/4.0/

\begin{abstract}
Diarrhea diseases remain the second leading cause of death among children under five years globally. Nearly one in every five child deaths, about 1.6 million each year, are due to diarrhea. Further, diarrhea kills more young children than malaria, measles and Acquired Immunodeficiency Syndrome (AIDS) combined. As a result, better understanding of childhood diarrhea occurrence can perhaps help reduce associated morbidity and mortality rates. Therefore, this study conducted a global systematic review on occurrence of childhood diarrhea. The broad objective of this study was to review present and past researches on childhood diarrhea and most importantly for children under 5 years of age. The review focused on understanding the burden of diarrhea, causes of childhood diarrhea and solutions to the disease. A systematic literature review was conducted using the databases of PubMed, CINAHL, Web of Science and Google Scholar. Search key terms used were childhood diarrhea, risk factors and intervention practices. Journal articles and related reports were filtered and limited from 2005 to 2020. Sixty-one reports and articles that met inclusion criteria were used in this review. Review found that, childhood diarrhea imposes economic costs on the health system and families. Also, repeated bouts of diarrhea can lead to malnutrition, stunting and delayed brain growth later in life and can lead to stress and tension to the affected households. The dependence on open water sources which are often contaminated with fecal materials was found as the major cause of the rising prevalence of childhood diarrhea. Other important factors were poor hygienic practices and lack of sanitation facilities contribute to the spread of diarrhea diseases. Improvements in the quality of drinking water, sanitation facilities and hygiene practices especially in low and middle income countries have been suggested by many studies as an intervention to reduce childhood diarrhea.
\end{abstract}

\section{Keywords}

Diarrhea, Risk Factors, Children under 5 Years, Intervention Measures 


\section{Introduction}

Diarrhea among children is defined as a disease with loose or watery stool three or more times during a 24-hour period, or a decrease in the consistency of the stool from that which is normal for the patient [1]. Though most episodes of childhood diarrhea are not always severe, acute cases can lead to significant fluid loss and dehydration. Consequently, deaths or other severe consequences can arise if fluids are not replaced at the first sign of diarrhea. Diarrhea is a disease caused by a wide range of pathogens, including, viruses, protozoa and bacteria [2]. There are several most life-threatening viral and bacterial pathogens affecting individuals in developing countries among them is rotavirus which is the leading cause of acute diarrhea, and is responsible for about 40 per cent of all hospital admissions due to diarrhea among children under five worldwide [3]. Major bacterial pathogens are E. coli, Shigella, Campylobacter and Salmonella [2]. Cryptosporidium has been the most frequently isolated protozoan pathogen among children and is frequently found among HIV-positive patients. Though cholera is often thought of as a major cause of child deaths due to diarrhea, most cases occur among adults and older children. According to World Health Organization (2008), Vibrio cholerae is endemic in multiple locations, including Africa and Asia, and is a cause of large-scale outbreaks [4].

According to [5], for the purpose of optimal case management and of epidemiological tracking, a diarrheal episode is often diagnosed according to symptoms and is classified into three categories: Acute watery diarrhea including cholera is associated with significant fluid loss and rapid dehydration in an infected individual. It usually lasts for several hours or days [6]. The pathogens that generally lead to acute watery diarrhea include $V$. cholerae or $E$. coli bacteria, as well as rotavirus. Bloody diarrhea, often referred to as dysentery, is marked by visible blood in the stools [6]. It is associated with intestinal damage and nutrient losses in an infected individual. The most common cause of bloody diarrhea is Shigella, a bacterial agent that is also the most common cause of severe cases and persistent diarrhea is an episode of diarrhea, with or without blood that lasts at least 14 days. Undernourished children and persons with other illnesses such as AIDS, are more likely to develop persistent diarrhea, which in turn, tends to worsen their condition [7].

Diarrhea remains the second leading cause of death among children under five years globally after pneumonia (Table 1). It accounts for nearly 1.3 million deaths a year among children under 5 years of age making it the second most common cause of childhood mortality globally [8]. According to WHO and UNICEF (2009), childhood diarrhea kills more young children than Acquired Immunodeficiency Syndrome (AIDS), malaria and measles combined [7]. In addition, an estimated 2.5 billion cases of diarrhea occur every year among children under five years of age, and estimates suggest that overall incidence has remained relatively stable over the past two decades [4]. Surprisingly, nearly three quarters of child deaths due to diarrhea occur in just 15 countries (Table 2). 
Table 1. Cause-specific deaths among children under five years of age worldwide [7].

\begin{tabular}{cccccccc}
\hline Disease & Pneumonia & Diarrhea & Neonatal causes & Malaria & measles & AIDS & Others \\
\hline $\begin{array}{c}\text { Percentage } \\
\text { of deaths }\end{array}$ & $17 \%$ & $16 \%$ & $37 \%$ & $4 \%$ & $4 \%$ & $2 \%$ & $4 \%$ \\
\hline
\end{tabular}

Table 2. Distribution of diarrhea cases among children under 5 years of age by country [7].

\begin{tabular}{ccc}
\hline Rank & Country & $\begin{array}{c}\text { Total number of annual child deaths } \\
\text { rank country due to diarrhea }\end{array}$ \\
\hline 1 & India & 386,600 \\
2 & Nigeria & 151,700 \\
3 & Democratic Republic of the Congo & 89,900 \\
4 & Afghanistan & 82,100 \\
5 & Ethiopia & 73,700 \\
6 & Pakistan & 53,300 \\
7 & Bangladesh & 50,800 \\
8 & China & 40,000 \\
9 & Uganda & 29,300 \\
10 & Kenya & 27,400 \\
11 & Niger & 26,400 \\
12 & Burkina Faso & 24,300 \\
13 & United Republic of Tanzania & 23,900 \\
14 & Mali & 20,900 \\
15 & Angola & 19,700 \\
\hline & & \\
\hline & &
\end{tabular}

According to World Health Organization 2009, India is the country that has the highest childhood diarrhea prevalence with more than 380,000 children die from diarrhea and its complications. However, India has made steady progress in reducing deaths in children under 5 years where this reduction has been possible due to inception and success to many universal programs such as expanded programs on immunization. Despite the decline, the proportional mortality accounted by diarrhea in India still remains high [9].

In Africa the burden of diarrhea remains high. Diarrhea disease remains the third leading cause of disease and death in children younger than 5 years of age. Diarrhea disease in Africa was responsible for an estimated 30 million cases of severe diarrhea and 330,000 deaths in 2015 [10]. Where, the frequency and severity of diarrhea in Africa is aggravated by lack of access to sufficient clean water, poor sanitation and hygiene practices. Additionally, in Kenya diarrhea diseases remains to be among the major public health problems where the mortality rate of children under the age of five years due to diarrhea is very high about $16 \%$ surpassing deaths from HIV and Malaria combined [11]. Further, according to KNBS and ICF Macro 2014, every child in Kenya under the age of five ex- 
periences an average of three bouts of diarrhea every year [12]. This is mostly associated with poor hygiene practices, poor sanitation facilities as well as poor supply of safe and clean drinking water where over $50 \%$ of hospital visits in Kenya for illnesses are related to Water, Sanitation and Hygiene (WASH).

Consequently, this study presents comprehensive information on diarrhea disease of under 5 years of age children by reviewing related past and present empirical studies. The review reveals vital information that can help to understand the burden of childhood diarrhea disease occurrence. Specifically, the study gives detailed review of childhood diarrhea disease contributable factors and appropriate intervention measures that can be used to prevent incidences of childhood diarrhea. Finally, the study gives the gaps and recommendation of the reviewed studies.

\section{Methodology}

This article is based on global review of both published and unpublished literature related to diarrhea disease among children under 5 years of age. Relevant published articles and reports were identified by using international databases including Google scholar, PubMed, Web of Science, China National Knowledge Infrastructure and Science Direct. Search key terms included: Childhood diarrhea, risk factors and intervention practices. Published articles and reports were limited from years 2005 to 2020. Sixty-one reports and journal articles reporting the prevalence and determinants of diarrhea among under-five children and met inclusion criteria were used to analyze the situation of global diarrhea.

\section{Discussion}

\subsection{Burden of Childhood Diarrhea}

Diarrhea disease is a global burden. According to [13], diarrhea is one of the most common childhood illnesses, in both developing and developed countries. While the disease is rarely a cause of death in developed countries, it is estimated that approximately 1.6 million children die each year from diarrhea in the developing world [13]. Countries in sub-Saharan Africa and South Asia account for almost $90 \%$ of global diarrheal deaths in children and a significant share of the total disease burden [13]. Evidence shows that diarrhea diseases disproportionately affect locations with poor access to health care, safe water, and sanitation, and low-income or marginalized countries [14]. For instance, in Kenya which as a low income country, diarrhea disease is a public health burden and remains among the top ten causes of under-five mortality and morbidity cases [15] with other African countries like Ethiopia and Somalia still experiences childhood diarrhea burden [16] [17] [18] [19] [20].

Further, repeated bouts of diarrhea can place a physical and emotional burden on the primary mothers or caregivers since they are responsible for all tasks in and around the household including the duty of caring for their children. A study that was done to survey the Caregivers Opinions and Perceptions of 
Workload in the Intensive Care Unit [21] reported they spend about 30\% of their workday in their households cleaning diarrhea. In the study, respondents reported that more than two caregivers were needed to clean diarrhea $70 \%$ of the time and $69 \%$ stated that this help was most often available. Unfortunately, staff examined reported that, they felt a lot of frustrations from cleaning diarrhea for about $50 \%$ of their time [21].

In addition to this, diarrhea can cause stress and tension in the households because of inflated financial costs related to efforts to cope with the illness. A study that was done in Rwanda to understand the economic burden attributable to a child's inpatient admission for diarrhea disease concluded that, households often bear the largest share of the economic burden attributable to diarrhea hospitalization and the burden can be substantial and especially for households in the lowest income quintile [22]. In addition to this, the complexity of diarrhea and the increasing cost of treatment puts additional burden on the health sector. This is showed in studies done in countries like in Kenya, where the costs of care and treatment for rotavirus gastroenteritis are high and rotavirus diarrhea leads to considerable resource utilization in health care settings and the society [23]. In Kenya, diarrhea infection causes 4471 deaths, 8781 hospitalizations, and $1,443,883$ clinic visits for diarrhea among children under 5 years of age annually. Nationally, rotavirus disease in Kenya costs the health care system $\$ 10.8$ million annually. Similarly, a study conducted in Ghana in hospital health care to determine the cost of diarrheal disease in northern Ghana [24], where the diarrhea associated costs were found to be high. A study carried out in 3 south Asia settings (Bangladesh, India and Pakistan) to estimate the costs borne by households due to childhood diarrhea, including direct medical costs, direct nonmedical costs, and productivity losses showed that childhood diarrhea creates economic burden for affected households [25]. According to the study, mean cost per diarrhea episode was $\$ 1.82$ in Bangladesh, \$3.33 in India, and \$6.47 in Pakistan where majority of costs for households were associated with direct medical costs from treatment [25].

Additionally, diarrhea among children younger than 5 years can lead growth faltering and can cause long-term disability. This is evidenced by a study done in assessing the non-fatal burden of childhood diarrhea where the study found out that diarrhea significantly increased the risk of subsequent physical growth and cognitive development impairment in the area [26]. The explanation of this is that, in malnourished children, exposure to multiple bouts of diarrheal illnesses may impair intestinal function. Persistent diarrhea has been also found to seriously affect nutritional status, growth, and intellectual function [27]. Other evidences show that childhood diarrhea, especially in the first 2 years of life, can negatively affect nutrient absorption, leading to poor physical growth [14] [28] [29].

\subsection{Childhood Diarrhea Risk Factors}

There are several factors that have been assessed to influence the occurrence of 
childhood diarrhea. These are broadly categorized as socio-economic (mother's age, number of children, occupation status, household size and education level), environmental (sources of drinking water, toilet facilities, water treatment) and behavioral (bottle feeding and hand washing with soap). Several studies have found that socioeconomic variables play a significant role in explaining the prevalence of childhood diarrhea. For example, studies that were done in Pakistan and in Mogadishu Somalia, found that children of more educated mothers or caregivers tend to have lower diarrhea prevalence, irrespective of water and sanitation conditions and this is because of better understanding of proper hygiene practices and correct feeding practices [20] [30]. Similarly, other studies done in Ghana and Kenya reported that childhood diarrhea occurrence was significantly lower where mothers had secondary education, compared to mothers with no education [31] [32]. This is similar to a study in Ethiopia which found out that, diarrhea cases among children under the age of 5 years were 3.97 times higher among children of mothers/caretakers who had not attended formal education compared with children whose mothers had attended formal education. This is similar to studies by [1] [33] which showed that mother's education was a significant determinant of childhood diarrhea. Another important socioeconomic factor which have been found to influence childhood diarrhea is occupational status of the mother/caregiver. A study conducted in Pakistan by [30] found that housewives mothers had more correct feeding practices as compared to employed mothers. The explanation of this being that, working mothers may find it difficult to manage their time for preparation of health nutritious meals and rather prefers pre-formed meal for their young ones thus weakening the immune system which leads to an increased susceptibility of children to diarrhea diseases and other infections. Other socio-demographic variables that significantly predicted lower diarrhea incidence among children under five included: higher household income [33], age of the child [1] [34] and the child's sex [34]. Another study found that children's gender and age to be a critical determinant of diarrhea incidences. This was evidenced on a study by [35], where girls more careful and practiced hand washing better than boys while older children practiced hand washing with soap much better than younger ones because they know the dangers. Number of children in a household was also found to be a factor contributing to childhood diarrhea. A study done in Ethiopia [17], reported that children from households with more than three under-five children were four times at risk of diarrhea compared to two or less under-five children in the households. This is because when there are fewer number of under-five children in the household's mothers/caregivers are influenced to provide adequate and timely childcare that with higher number of children where mothers might have difficulties for taking care of a large number of children. These findings are similar to another study in Nyeri county [32].

A number of studies found association between environmental variables as intervening variable explaining childhood diarrhea incidence. For example, 
non-protected sources of drinking water have been significantly associated with an increased risk of diarrhea in a number of studies [36] [37]. The explanation of this being that, unprotected water sources get easily contaminated by runoff making the water unbiologically safe for drinking. Another study found childcare institutions which used water from rains and shallow wells had $86.7 \%$ diarrheal diseases [34]. Other studies have identified the availability of latrine among households to reduce childhood diarrhea [32] [36] [37]. A study in Ghana found that children who lived in in-house built toilets were $50 \%$ less likely to contract diarrhea diseases than those who used outside toilets [38]. According to the results of a study done in Dale district in Ethiopia reported that, the odds of having diarrhea diseases among children under the age of 5 years were 3.23 times higher among children from households that disposed refuse improperly compared with the odds of diarrheal diseases among children from households which properly disposes of refuse [39]. This is because refuse may contain different pathogens which can cause diarrhea diseases and also creates a suitable site for insects breeding. As a result, improper refuse disposal may increase the chance of contact of insect vectors from refuse to food items worsening sanitation and hygiene of entire family.

An association between maternal hygiene and behavioral variables and rates of childhood diarrhea has also been demonstrated in number of studies. For instance, a study that was conducted in Kenya found that, hand washing using soap after toilet increase reduced diarrheal diseases [34]. A study in Dejen District, Ethiopia found out that, children from mothers who washed their hands with water only were nearly twice more likely to develop diarrhoeal disease when compared to those children whose mothers had hand washing practice with water and soap/ash [36]. This is similar to a study done in Arba Minch which reported that mothers with poor hand washing practices were significantly associated with childhood diarrhoeal disease [1]. Immunization of children has also been found to be a significant factor in explaining the childhood diarrhea incidence. A study in Nyarugenge district, Rwanda found that children who had not been vaccinated for Rotavirus were 8 times more likely to develop diarrheal diseases than to those who were vaccinated [31]. Also, house floor material has been found to significantly affect the occurrence of childhood diarrhea. A study done in Dale district in Ethiopia showed that, developing diarrheal diseases among children under the age of 5 years were 3.22 times higher among children dwelling in Mud floor households as compared with children whose household dwelling was with cement floor [39]. And the explanation of this could be due to housing with cement floor is considered as a clean home environment. According to a study in Zana district in Ethiopia found that child feeding practices were also significantly associated with childhood diarrhea in which children who did not exclusively breastfeed and initiated complementary feeding above 6 months of age were five and two-folds at risk of diarrhea, respectively compared to their counterparts [17]. These findings are in agreement with similar findings done elsewhere in Mecha District, Ethiopia [31]. 
A brief summary on factors reported to influence childhood diarrhea is as shown (Figure 1).

\subsection{Diarrhea Intervention Practices}

Many studies have been carried out to investigate on intervention measures that can be undertaken to reduce childhood diarrhea. Washing hands with soap, increasing access to safe water for drinking, improving water quality at the source, treating household water and storing it safely and disposing of human excreta in a sanitary manner to avoid contamination cases are among prevention practices found to reduce number of childhood diarrhea cases. For instance, improving sanitation facilities has been associated with a reduction in diarrhea incidence across reviewed studies [40] [41]. The implication of this is that, improvements of sanitation facilities can reduce the transmission of pathogens that cause diarrhea by preventing human fecal matter from contaminating environments. Providing formal education to mothers or caregivers also helps reduce the cases of childhood diarrhea. This could be explained by maternal educational status persuades the personal and environmental hygienic practices, child feeding and caring practices, improving living conditions and reducing resistance for new ways of delivery for prevention and control of communicable diseases interventions like health extension programs [17]. Washing one's hands with soap is another important barrier to transmission and has been cited as one of the most cost-effective intervention for reducing incidence of diarrhea among children under 5 years. Similarly, a number of studies [41] [42] [43] have shown that

\section{Independent Variables}

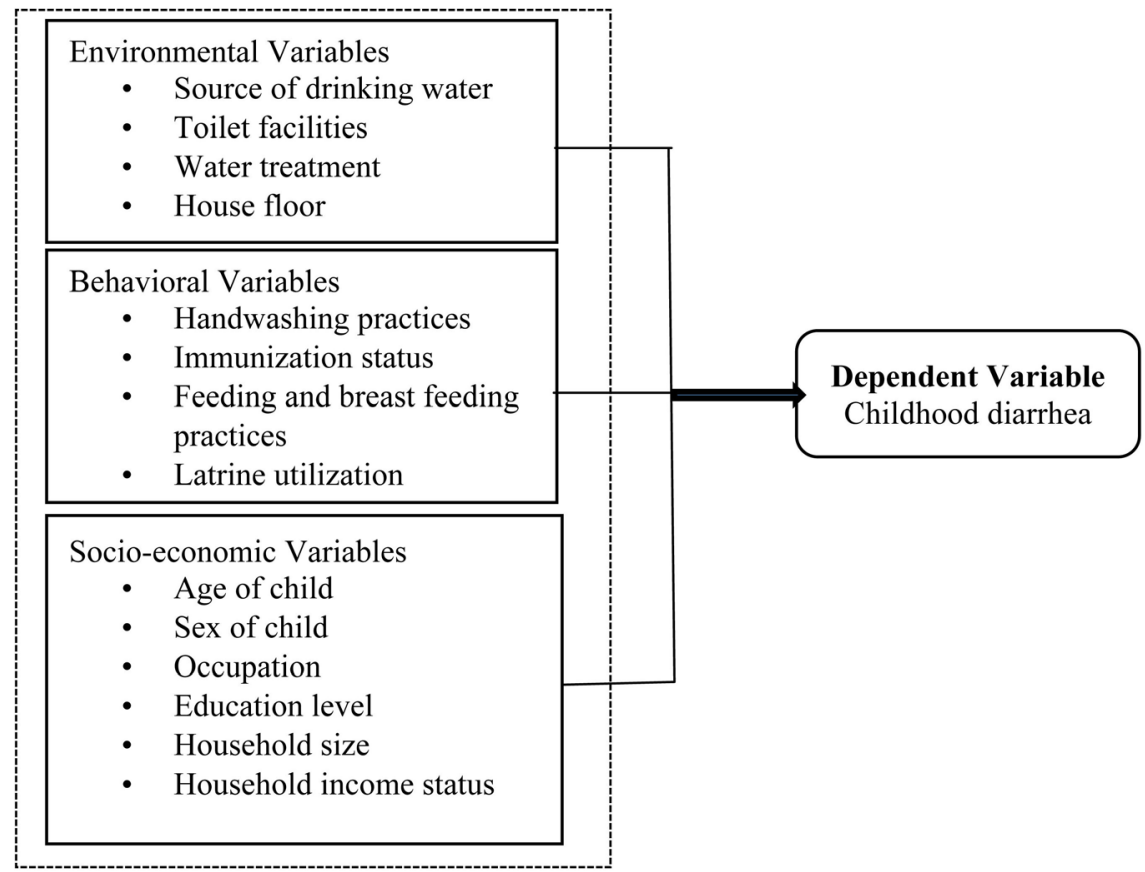

Figure 1. Determinants of diarrhea among under five years. 
handwashing with soap can reduce the incidence of childhood diarrhea disease. In agreement with this study, another study also reported as handwashing with soap particularly before eating, preparing food and feeding children and after using the toilet can considerably reduce the risk of diarrhea [18]. This is can be explained as soap breaks down grease and dirt that carry germs and disease-causing pathogens [18].

Additionally, access to plentiful water has been also shown to encourage better hygiene, handwashing in particular, although the extent to which access to improved water sources reduces diarrhea rates often depends on the type of water source available (such as public taps or standpipes, protected dug wells or boreholes) [40] [44]. Further, interventions to improve water quality at the source, along with treatment of household water and safe storage systems have been shown to reduce diarrhea incidence. Proven and field-tested household water treatment options that are currently being promoted include chlorination, filtration, combined flocculation and disinfection, boiling, and solar disinfection [43] [45] [46] [47]. Household water treatment could potentially be scaled up quickly and inexpensively in both development and emergency situations. It has even become common practice in large cities where homes are connected to a municipal water supply, since water is often polluted between the source and the point of use. In addition to this, ensuring a clean home environment for the children has been also found critical in reducing the transmission of pathogens that cause diarrheal diseases [39].

Regarding maternal/caregiver health and caring practices, proper breastfeeding and appropriate timing on children practices can help prevent childhood diarrhea incidences [17]. This is because proper breast feeding and initiation of complementary feeding on 6th months provide protective factors that could help reduce various infections including diarrhea. This also strengthens the immunity of children which indirectly reduces diarrhea causative organism(s) accidentally introduced into supplementary foods during feeding practices and due to unhygienic procedures in the preparation of feeds, materials and types of water used [17]. Finally, although water, sanitation and hygiene related interventions have been found to successfully reduce the global burden of diarrhea, one main cause of diarrhea mortality, rotavirus is not prevented using these interventions [48]. Rotavirus is associated with approximately one third of diarrhea deaths and can only be adequately prevented through vaccination [48]. Therefore, according to [48], vaccination has been reported as the strongest protection against vaccine-preventable causes of diarrhea among children under 5 years globally.

\section{Conclusions}

Diarrheal disease among under-five children is significantly high and has been identified as the major cause of mortality and morbidity worldwide [7]. The review established that, childhood diarrhea is a global burden and is significantly higher in low and middle income countries like Kenya which are highly asso- 
ciated with lack or inadequate clean water for drinking as well as poor sanitation facilities and hygiene practices [4]. Additionally, the review found that, the significant independent variables associated with diarrheal diseases among children under the age of 5 years are educational status of mother/caretakers, occupational status of the mother, housing floor material, source and quality of domestic water, gender and age of the child, methods of hand washing, refuse disposal methods amongst others [31] [32] [33] [34]. These findings have been found to have important policy implications for childhood diarrhoeal disease intervention programs. Therefore, interventions such as proper handwashing techniques at all appropriate times, water treatment and practicing safe storage, improving nutrition and better child care are highly evidenced to reduce childhood diarrhea and especially in African countries [39]-[49]. Also, the review established health educations about personal hygiene as well as proper disposal of wastes including excreta in integration with the existing national health extension program like child immunization as an intervention that can reduce mortality and morbidity cases of childhood diarrhea [31] [32]. Unfortunately, the costs related to achieving better hygiene and sanitation facilities still remain high [24] [49], hence only few people can afford and therefore many individuals rely on the available facilities irrespective of their biological, chemical and physical state. Consequently, this has been the reason why diarrhea disease has taken over other diseases to being one of the leading causes of deaths and illness among children under 5 years globally.

However, the analysis of childhood diarrhea and associated risk factors has become a concern all in both developed and developing countries. For instance, a number of studies in developing countries [16] [19] [20] [50] [51] have been carried out to study diarrhea disease among children under 5 years. However, most of them so far have focused exclusively on the risk factors that cause the disease and how the disease can be prevented. Although these studies are very crucial in understanding the burden of childhood diarrhea disease and its effects on the affected individual, they fail to explain the spatial-temporal relationship of the identified factors as well as the spatial relationship between the factors and diarrhea incidence. Further, such studies also fail to delineate territories of high and low risk of the childhood diarrhea disease which is usually very useful to health care officials. Disease level differ substantially from one area to another and it is therefore essential to characterize these areal variations and delineate areas of hot spots and cold spots to allow appropriate public health policy decisions [52]. According to [53] [54], improvements in Geographical Information Systems (GIS) technology offers numerous opportunities for epidemiologists to study the spatial distribution of diseases and also understand the relationships between socio-economic, behavioral and environmental factors and the occurrence of diseases. For instance, GIS techniques have been employed in the investigation and monitoring of vector-borne diseases [55] [56], health education [57] waterborne diseases [58] [59], as well as in environmental health [60] [61]. Geospatial Information System is a software that links geographic information 
with descriptive information [62]. It provides, efficient, fast and easier to use functions which enable integration of various data sources their harmonization and combined analysis towards achieving a particular objective [62]. In addition, GIS helps in the initial identification of the main cause, visualization and analyze the spatial relationship between various factors explaining a certain dependent phenomenon.

\section{Acknowledgements}

Many thanks to my lecturer Charles W. Recha for his advice and improvements he made on this paper. My utmost gratitude to Stephen M'masi. His useful comments are highly appreciated.

\section{Conflicts of Interest}

The authors declare no conflicts of interest regarding the publication of this paper.

\section{References}

[1] Mohammed, S., Tilahun, M. and Tamiru, D. (2013) Morbidity and Associated Factors of Diarrheal Diseases among Under-Five Children in Arba-Minch District, Southern Ethiopia, 2012. Science Journal of Public Health, 1, 102-106. https://doi.org/10.11648/j.sjph.20130102.19

[2] Ahs, J.W., Tao, W., Löfgren, J. and Forsberg, B.C. (2010) Diarrheal Diseases in Lowand Middle-Income Countries: Incidence, Prevention and Management. The Open Infectious Diseases Journal, 4, 113-124. https://doi.org/10.2174/1874279301004010113

[3] Parashar, U.D., Gibson, C.J., Bresee, J.S. and Glass, R.I. (2006) Rotavirus and Severe Childhood Diarrhea. Emerging Infectious Diseases, 12, 304-306. https://doi.org/10.3201/eid1202.050006

[4] Boschi-Pinto, C., Velebit, L. and Shibuya, K. (2008) Estimating Child Mortality Due to Diarrhoea in Developing Countries. Bulletin of the World Health Organization, 86, 710-717. https://doi.org/10.2471/BLT.07.050054

[5] Keusch, G.T., et al. (2006) Chapter 19. Diarrheal Diseases. In: Disease Control Priorities in Developing Countries, 2nd Edition, Oxford University Press, Oxford, 371-388. https://doi.org/10.1596/978-0-8213-6179-5/Chpt-19

[6] DuPont, H.L. (2008) Diarrheal Diseases (Acute). Cambridge World History Human Disease, 676-680.

[7] WHO and UNICEF (2009) Diarrhoea: Why Children Are Still Dying and What Can Be Done.

[8] Soiza, R.L., Donaldson, A.I.C. and Myint, P.K. (2018) Vaccine against Arteriosclerosis: An Update. Therapeutic Advances in Vaccines, 9, 259-261.

https://doi.org/10.1177/2042098618769568

[9] Lakshminarayanan, S. and Jayalakshmy, R. (2015) Diarrheal Diseases among Children in India: Current Scenario and Future Perspectives. Journal of Natural Science, Biology, and Medicine, 6, 24-28. https://doi.org/10.4103/0976-9668.149073

[10] Reiner, R.C., et al. (2018) Variation in Childhood Diarrheal Morbidity and Mortality in Africa, 2000-2015. The New England Journal of Medicine, 379, 1128-1138. 
[11] Samwel, M., Eddison, M., Faith, N., Richard, S., Elizabeth, M. and Douglas, N. (2014) Determinants of Diarrhea among Young Children under the Age of Five in Kenya, Evidence from KDHS 2008-09. Etude la Popul Africaine, 28, 1046-1056. https://doi.org/10.11564/28-0-556

[12] KDHS (2014) KDHS. Social Welfare in Africa, 1-358.

[13] Naghavi, M., et al. (2017) Global, Regional, and National Age-Sex Specific Mortality for 264 Causes of Death, 1980-2016: A Systematic Analysis for the Global Burden of Disease Study 2016. The Lancet, 390, 1151-1210.

[14] Troeger, C., et al. (2017) Estimates of Global, Regional, and National Morbidity, Mortality, and Aetiologies of Diarrhoeal Diseases: A Systematic Analysis for the Global Burden of Disease Study 2015. The Lancet Infectious Diseases, 17, 909-948.

[15] MOH (2014) Kenya Environmental Sanitation and Hygeine Policy (Draft).

[16] Kabew, G., Mengistie, B., Mulat, W. and Sahilu, G. (2019) Risk Factors for Acute Childhood Diarrhea: A Cross-Sectional Study Comparing Refugee Camps and Host Communities in Gambella Region, Ethiopia. Travel Medicine and Infectious Disease, 31, Article ID: 101385. https://doi.org/10.1016/j.tmaid.2019.02.003

[17] Asfaha, K.F., et al. (2018) Determinants of Childhood Diarrhea in Medebay Zana District, Northwest Tigray, Ethiopia: A Community Based Unmatched Case-Control Study. BMC Pediatrics, 18, 120. https://doi.org/10.1186/s12887-018-1098-7

[18] Ayele, A., Awoke, W. and Tarekegn, M. (2014) Crossectional Survey; Assessment of Diarrheal Disease. Global Journal of Medical Research F. Diseases, 14.

[19] Children, U. (2018) Factors Related to the Occurrence of Diarrheal Disease in Under-Five Children of IDP's in Bosaso, Puntland-Somalia Factors Related to the Occurrence of Diarrheal Disease in 2016.

[20] Fartun Osman, M.S., Abdirisaq, H. and Abdirahman, M. (2017) Factors Influencing the Occurrence of Diarrhoea among Children under the Age of Five Admitted to Benadir Hospital Mogadishu-Somalia. Vol. 1.

[21] Heidegger, C.P., Graf, S., Perneger, T., Genton, L., Oshima, T. and Pichard, C. (2016) The Burden of Diarrhea in the Intensive Care unit (ICU-BD): A Survey and Observational Study of the Caregivers' Opinions and Workload. International Journal of Nursing Studies, 59, 163-168. https://doi.org/10.1016/j.ijnurstu.2016.04.005

[22] Ngabo, F., et al. (2016) The Economic Burden Attributable to a Child's Inpatient Admission for Diarrheal Disease in Rwanda. PLOS ONE, 11, e0149805. https://doi.org/10.1371/journal.pone.0149805

[23] Osano, B.O., Wang'ombe, J.K., Kamenwa, R.W. and Wamalwa, D. (2011) Cost Analysis of Care for Children Admitted to Kenyatta National Hospital with Rotavirus Gastroenteritis. Vaccine, 29, 4019-4024.

https://doi.org/10.1016/j.vaccine.2011.03.053

[24] Aikins, M., Armah, G., Akazili, J. and Hodgson, A. (2010) Hospital Health Care Cost of Diarrheal Disease in Northern Ghana. The Journal of Infectious Diseases, 202, S126-S130. https://doi.org/10.1086/653573

[25] Rheingans, R., et al. (2012) Determinants of Household Costs Associated with Childhood Diarrhea in 3 South Asian Settings. Clinical Infectious Diseases, 55, S327-S335. https://doi.org/10.1093/cid/cis764

[26] Khalil, A.-M., Troeger, C., Rao, P., Forouzanfar, M., Columbara, D., Misra, K. and Mokdad, A. (2016) Assessing the Nonfatal Burden of Childhood Diarrhea Including Malnutrition, Physical Growth, and Cognitive Development. Open Forum Infec- 
tious Diseases, 3, 1220. https://doi.org/10.1093/ofid/ofw172.923

[27] Ochoa, T.J., Salazar-Lindo, E. and Cleary, T.G. (2004) Management of Children with Infection-Associated Persistent Diarrhea. Seminars in Pediatric Infectious Diseases, 15, 229-236. https://doi.org/10.1053/j.spid.2004.07.003

[28] Steinhoffa, M.C. (2018) Interactions of Diarrhea, Pneumonia, and Malnutrition in Childhood: Recent Evidence from Developing Countries. Physiology \& Behavior, 176, 139-148.

[29] Kassebaum, N.J., et al. (2019) Diseases, Injuries, and Risk Factors in Child and Adolescent Health, 1990 to 2017: Findings from the Global Burden of Diseases, Injuries, and Risk Factors 2017 Study. JAMA Pediatrics, 173, e190337.

[30] Afzal, A. (2017) Association of Socio-Demographic Factors with Dietary Practices of Mothers in Under-Five Children with Diarrhea. International Journal of Biotechnology and Bioengineering, 3, 236-241. https://doi.org/10.25141/2475-3432-2017-6.0230

[31] Habtu, M., et al. (2017) Factors Contributing to Diarrheal Diseases among Children Less than Five Years in Nyarugenge District, Rwanda. Journal of Tropical Diseases, 5,3 .

[32] Asfaha, K.F., Tesfamichael, F.A., Fisseha, G.K., Misgina, K.H., Weldu, M.G., Welehaweria, N.B. and Gebregiorgis, Y.S. (2018) Determinants of Childhood Diarrhea in Medebay Zana District, Northwest Tigray, Ethiopia: A Community Based Unmatched Case-Control Study. BMC Pediatrics, 18, 1-9.

https://doi.org/10.1186/s12887-018-1098-7

[33] Connell, B.J.O., Quinn, M.A. and Scheuerman, P. (2017) Risk Factors of Diarrheal Disease among Children in the East African Countries of Burundi, Rwanda and Tanzania. Global Journal of Medicine and Public Health, 6, 1.

[34] Mamboleo, D.M., Njoroge, S.M. and Okaru, F.N. (2016) The Prevalence of Diarrheal Diseases in Childcare Institutions, Uasin Gishu The Prevalence of Diarrheal Diseases in Childcare Institutions, Uasin Gishu County, Kenya.

[35] Danquah, L., Curtis, V. and Aunger, R. (2007) What Do We Know about Hand Washing Practices? Hygiene Centre for Unilever PLC.

[36] Getu, D., Gedefaw, M. and Abebe, N. (2014) Childhood Diarrheal Diseases and Associated Factors in the Rural Community of Dejen District, Northwest Ethiopia, 2014. American Scientific Research Journal for Engineering, Technology, and Sciences, 5, 1-13.

[37] Id, S.Y., Hudani, A., Udenigwe, O. and Shah, V. (2018) Improving Water, Sanitation and Hygiene Practices, and Housing Quality to Prevent Diarrhea among Under-Five Children in Nigeria. Tropical Medicine and Infectious Disease, 3, 41.

[38] Hung, B.V. (2006) The Most Common Causes of and Risk Factors for Diarrhea among Children Less than Five Years of Age Admitted to Dong Anh Hospital, Hanoi, Northern Vietnam.

[39] Melese, B., Paulos, W., Astawesegn, F.H. and Gelgelu, T.B. (2019) Prevalence of Diarrheal Diseases and Associated Factors among Under-Five Children in Dale District, Sidama Zone, Southern Ethiopia: A Cross-Sectional Study. BMC Public Health, 19, Article No. 1235. https://doi.org/10.1186/s12889-019-7579-2

[40] Esrey, S.A., Feachem, R.G. and Hughes, J.M. (1985) Interventions for the Control of Diarrhoeal Diseases among Young Children: Improving Water Supplies and Excreta Disposal Facilities. Bulletin of the World Health Organization, 63, 757-772.

[41] Fewtrell, L., Kaufmann, R.B., Kay, D., Enanoria, W., Haller, L. and Colford, J.M. (2005) Water, Sanitation, and Hygiene Interventions to Reduce Diarrhoea in Less 
Developed Countries: A Systematic Review and Meta-Analysis. The Lancet Infectious Diseases, 5, 42-52. https://doi.org/10.1016/S1473-3099(04)01253-8

[42] Ri, E., Je, E., Arikpo, D., Mm, M. and Ja, C. (2015) Hand Washing Promotion for Preventing Diarrhoea. Cochrane Database of Systematic Reviews, No. 9, CD004265.

[43] Luby, S.P., et al. (2006) Combining Drinking Water Treatment and Hand Washing for Diarrhoea Prevention, a Cluster Randomised Controlled Trial. Tropical Medicine \& International Health, 11, 479-489. https://doi.org/10.1111/j.1365-3156.2006.01592.x

[44] Garrett, V., et al. (2008) Diarrhoea Prevention in a High-Risk Rural Kenyan Population through Point-of-Use Chlorination, Safe Water Storage, Sanitation, and Rainwater Harvesting. Epidemiology \& Infection, 136, 1463-1471. https://doi.org/10.1017/S095026880700026X

[45] Arnold, B.F. and Colford, J.M. (2007) Treating Water with Chlorine at Point-of-Use to Improve Water Quality and Reduce Child Diarrhea in Developing Countries: A Systematic Review and Meta-Analysis. American Journal of Tropical Medicine and Hygiene, 76, 354-364. https://doi.org/10.4269/ajtmh.2007.76.354

[46] Lule, J.R., et al. (2005) Effect of Home-Based Water Chlorination and Safe Storage on Diarrhea among Persons with Human Immunodeficiency Virus in Uganda. American Journal of Tropical Medicine and Hygiene, 73, 926-933. https://doi.org/10.4269/ajtmh.2005.73.926

[47] Quick, R.E., et al. (2002) Diarrhea Prevention through Household-Level Water Disinfection and Safe Storage in Zambia. American Journal of Tropical Medicine and Hygiene, 66, 584-589. https://doi.org/10.4269/ajtmh.2002.66.584

[48] Lamberti, L.M., Ashraf, S., Walker, C.L.F. and Black, R.E. (2016) A Systematic Review of the Effect of Rotavirus Vaccination on Diarrhea Outcomes among Children Younger than 5 Years. The Pediatric Infectious Disease Journal, 35, 992-998. https://doi.org/10.1097/INF.0000000000001232

[49] Bin Halim, F. and Haider, M.Z. (2017) Prevalence and Economic Costs of Diarrheal Illness among Adult Slum Dwellers in Khulna City, Bangladesh. Journal of Health and Social Sciences, 120, 83-98.

[50] Musoke, D., Ndejjo, R., Halage, A.A., Kasasa, S., Ssempebwa, J.C. and Carpenter, D.O. (2018) Drinking Water Supply, Sanitation, and Hygiene Promotion Interventions in Two Slum Communities in Central Uganda. Journal of Environmental and Public Health, 2018, Article ID: 3710120. https://doi.org/10.1155/2018/3710120

[51] Njeru, P.M., Kariri, J.M., Murigi, M.W., Waweru, H.M. and Muriithi, F.M. (2017) Management of Diarrheal Diseases among Children under Five Years: A Case Study of Mothers at Kakamega County, Kenya. International Journal of Community Medicine and Public Health, 4, 2762. https://doi.org/10.18203/2394-6040.ijcmph20173319

[52] Musa, G.J., et al. (2013) Use of GIS Mapping as a Public Health Tool-From Cholera to Cancer. Health Services Insights, 6, 111-116. https://doi.org/10.4137/HSI.S10471

[53] Croner, C.M. (2003) Public Health, GIS, and the Internet. Annual Review of Public Health, 24, 57-82. https://doi.org/10.1146/annurev.publhealth.24.012902.140835

[54] ESRI (2005) Approaches to GIS Programs In Health Education.

[55] Pathirana, S., Kawabata, M. and Goonatilake, R. (2009) Study of Potential Risk of Dengue Disease Outbreak in Sri Lanka Using GIS and Statistical Modelling. Journal of Rural and Tropical Public Health, 8, 8-17. 
[56] Kala, A.K., Tiwari, C., Mikler, A.R. and Atkinson, S.F. (2017) A Comparison of Least Squares Regression and Geographically Weighted Regression Modeling of West Nile Virus Risk Based on Environmental Parameters. PeerJ, 5, e3070. https://doi.org/10.7287/peerj.preprints.2673

[57] Shanmugam, G. (2018) WASH (Water, Sanitation and Hygiene). International Journal of Trend in Scientific WASH(Water, Sanitation and Hygiene), 2, 577.

[58] Osei, F.B. and Duker, A.A. (2008) Spatial Dependency of $V$. cholera Prevalence on Open Space Refuse Dumps in Kumasi, Ghana: A Spatial Statistical Modelling. International Journal of Health Geographics, 7, 62. https://doi.org/10.1186/1476-072X-7-62

[59] Nkeki, F.N. and Osirike, A.B. (2013) GIS-Based Local Spatial Statistical Model of Cholera Occurrence: Using Geographically Weighted Regression. Journal of Geographic Information System, 5, 531-542. https://doi.org/10.4236/jgis.2013.56050

[60] Maantay, J. (2002) Mapping Environmental Injustices: Pitfalls and Potential of Geographic Information Systems in Assessing Environmental Health and Equity. Environmental Health Perspectives, 110, 161-171. https://doi.org/10.1289/ehp.02110s2161

[61] Chakraborty, J., Maantay, J.A. and Brender, J.D. (2011) Disproportionate Proximity to Environmental Health Hazards: Methods, Models, and Measurement. American Journal of Public Health, 101, S27-S36. https://doi.org/10.2105/AJPH.2010.300109

[62] ESRI (2012) What Is GIS? 